\title{
SOME INEQUALITIES FOR THE NONLINEAR MATRIX EQUATIONS
}

\section{LINLIN ZHAO}

Abstract. The nonlinear matrix equations $X \pm A^{*} X^{-1} A=Q$ have many applications in control theory, dynamic programming and statistics. In the present work, by using some related matrix equalities and linear algebraic techniques, we propose some trace and determinant inequalities for the solution of the above nonlinear matrix equations. Furthermore, we give some inequalities for the eigenvalues of their solutions.

Mathematics subject classification (2010): 15A15, 15A18, 15A24. solution.

Keywords and phrases: Nonlinear matrix equation, trace, determinant, eigenvalue, positive definite

\section{REFERENCES}

[1] J. CAi And G. L. Chen, Some investigation on Hermitian poitive definite solutions of the matrix equation $X^{s}+A^{*} X^{-t} A=Q$, Linear Algebra Appl. 430 (2009), 2448-2456.

[2] X. F. Duan And A. P. LiaO, On the nonlinear matrix equation $X+A^{*} X^{-q} A=Q(q \geqslant 1)$, Mathematical and Computer Modelling 49 (2009), 936-945.

[3] Z. G. JiA AND M. S. WeI, Solvability and sensitivity analysis of polynomial matrix equation $X^{s}+$ $A^{*} X^{t} A=Q$, Appl. Math. Comput. 209 (2009), 230-237.

[4] N. KomAROFF, Simultaneous eigenvalue lower bounds for the Riccati matrix equation, IEEE Trans. Automat. Control 34 (1989), 175-177.

[5] B. H. Kwon, M. J. Youn And Z. Bien, On bounds of the Riccati and Lyapunov matrix equations, IEEE Trans. Automat. Control 30 (1985), 1134-1135.

[6] A. J. LiU AND G. L. CHEN, On the Hermitian positive definite solutions of nonlinear matrix equation $X^{s}+A^{*} X^{t_{1}} A+B^{*} X^{t_{2}} B=Q$, Mathematical Problems in Engineering, DOI: 10.1155/2011/163585.

[7] T. Mori, N. Fukuma AND M. KuWAhara, On the discrete Lyapunov matrix equation, IEEE Trans. Automat. Control 27 (1982), 463-464.

[8] E. Y. SHAPIRo, On the Lyapunov matrix equation, IEEE Trans. Automat. Control Technical Notes and Correspondence (1974), 594-596.

[9] X. Z. Zhan AND J. J. XIE, On the matrix equation $X+A^{T} X^{-1} A=I$, Linear Algebra Appl. 247 (1996), 337-345.

[10] D. M. Zhou, G. L. Chen, G. X. Wu And X. Y. Zhang, Some properties of the nonlinear matrix equation $X^{s}+A^{*} X^{-t} A=Q$, J. Math. Anal. Appl. 392 (2012), 75-82. 